\title{
Loss of Endothelium-dependent Relaxant Activity in the Pulmonary Circulation of Rats Exposed to Chronic Hypoxia
}

\author{
Serge Adnot, * Bernadette Raffestin, ${ }^{*}$ Saadia Eddahibi, * Pierre Braquet, ${ }^{\star}$ and Pierre-Etienne Chabrier \\ *Département de Physiologie et Unité de Recherche de Physiologie Respiratoire, INSERM U 296, \\ Hôpital Henri Mondor, 94010 Creteil; and ${ }^{\ddagger}$ Institut Henri Beaufour, 91952 Les Ulis, France
}

\begin{abstract}
To determine whether exposure to chronic hypoxia and subsequent development of pulmonary hypertension induces alterations of endothelium-dependent relaxation in rat pulmonary vascular bed, we studied isolated lung preparations from rats exposed to either room air (controls) or hypoxia (H) during 1 wk (1W-H), 3 wk (3W-H), or $3 \mathrm{~W}-\mathrm{H}$ followed by $48 \mathrm{~h}$ recovery to room air $(3 W H+R)$. In lungs pretreated with meclofenamate $(3 \mu \mathrm{M})$, the endothelium-dependent vasodilator responses to acetylcholine $\left(10^{-9}-10^{-6} \mathrm{M}\right)$ and ionophore $\mathrm{A23187}\left(\mathbf{1 0}^{-9}\right.$ $10^{-7} \mathrm{M}$ ) were examined during conditions of increased tone by U46619 (50 pmol/min). Acetylcholine or A23187 produced dose-dependent vasodilation in control lungs, this response was reduced in group $1 \mathrm{~W}-\mathrm{H}(P<0.02)$, abolished in group $3 \mathrm{~W}-\mathrm{H}$ $(P<0.001)$, and restored in group $3 W H+R$. In contrast, the endothelium-independent vasodilator agent sodium nitroprusside remained fully active in group $3 W-H$. The pressor response to $300 \mathrm{pM}$ endothelin was greater in group $3 \mathrm{~W}-\mathrm{H}$ than in controls $(6.8 \pm 0.5 \mathrm{mmHg}$ vs. $1.6 \pm 0.2 \mathrm{mmHg}, P<0.001)$ but was not potentiated by the endothelium-dependent relaxing factor (EDRF) antagonists: hydroquinone $\left(10^{-4} \mathrm{M}\right)$; methylene blue $\left(10^{-4} \mathrm{M}\right)$; and pyrogallol $\left(3 \times 10^{-5} \mathrm{M}\right)$ as it was in controls. It was similar to controls in group $3 W-H+R$. Our results demonstrate that hypoxia-induced pulmonary hypertension is associated with a loss of EDRF activity in pulmonary vessels, with a rapid recovery on return to a normoxic environment. ( $J$. Clin. Invest. 1991. 87:155-162.) Key words: pulmonary hypertension • pulmonary endothelium • endothelium-derived relaxing factor $\bullet$ acetylcholine $\bullet$ endothelin
\end{abstract}

\section{Introduction}

In residents at high altitude or in patieńts suffering from chronic lung disease, exposure to chronic hypoxia leads to development of sustained pulmonary hypertension as a consequence of increased vasomotor tone and structural remodeling of the pulmonary vascular bed (1-3). Whereas hypoxia-induced pulmonary hypertension is known to be associated with both medial and intimal changes of pulmonary vessels in experimental animals (4-6), interactions between pulmonary vascular endothelium and vascular smooth muscle have not been

Address correspondence to Dr. Serge Adnot, Service des Explorations Fonctionnelles, Hôpital Henri Mondor, 94010 Creteil, France.

Received for publication 13 March 1990 and in revised form 25 July 1990

J. Clin. Invest.

(C) The American Society for Clinical Investigation, Inc.

$0021-9738 / 91 / 01 / 0155 / 08 \$ 2.00$

Volume 87, January 1991, 155-162 examined during hypoxic pulmonary hypertension. It is now understood that vascular endothelium, in addition to being a physical and metabolic barrier for circulating substances in the blood, can also influence the tone of the underlying smooth muscle (7). Endothelium-derived relaxing factor (EDRF), ${ }^{1}$ identified as nitric oxide or a related molecule, prostaglandins, and the vasoconstrictor peptide endothelin are all released by the endothelium and can influence smooth muscle tone in blood vessels (7-10). Whereas the role of pulmonary prostaglandins has been extensively investigated $(11,12)$, the potential role of EDRF and endothelin in the modulation of the pulmonary vascular tone was more recently suggested. Endothelium-dependent relaxation of vascular smooth muscle has been demonstrated in pulmonary vessels in response to acetylcholine, bradykinin, or other agents (13-15) as has the synthesis by pulmonary endothelium of the constrictor peptide endothelin (16). Potentiation of hypoxic pulmonary vasoconstriction by antagonists of endothelium-dependent relaxation has also been shown in the isolated perfused rat lung suggesting a concomitant release of EDRF during acute hypoxia (17-19). Moreover, the pulmonary vasoconstrictor response to endothelin (20) is potentiated by endothelium removal in isolated pulmonary arteries and by EDRF antagonists in isolated rat lungs $(21,22)$. These observations suggest that the release of EDRF could occur in response to pulmonary vasoconstriction induced by various stimuli and could contribute to the maintenance of a low resting tone in the pulmonary circulation. In the present study, we questioned whether endothelial alterations observed during exposure to moderate hypoxia could be associated with impaired endothelium-dependent relaxation in the pulmonary circulation. To test this hypothesis, we used isolated lung preparations from rats previously exposed to chronic hypoxia or room air and examined the pulmonary vascular response to the endothelium-dependent vasodilators, acetylcholine and ionophore A23187, and to the direct acting vasodilator agent sodium nitroprusside. We also compared the pressor effect of endothelin in lungs from normoxic and chronically hypoxic rats and examined whether EDRF antagonists, which potentiate vasoconstriction to endothelin in lungs from normoxic rats, had a similar effect in lungs from hypoxic animals.

\section{Methods}

\section{Chronic hypoxia}

Male Wistar rats weighing 250-300 g at the start of the experiment were randomly divided into four groups. Three groups of rats were exposed to chronic hypoxia and one group maintained in room air (control normoxic group). All hypoxic and normoxic rats were kept in the same

1. Abbreviations used in this paper: EDRF, endothelium-derived relaxing factor; HQ, hydroquinone; MB, methylene blue; Pyr, pyrogallol. 
room, at the same light-dark cycle. Rat chow and tapwater were provided ad libitum. Rats were exposed to hypoxia $\left(10-11 \% \mathrm{O}_{2}\right)$ in a 500 liter ventilated chamber (Flufrance apparatus, Cachan, France). To establish the hypoxic environment, the chamber was flushed with a mixture of room air and nitrogen and gas recirculated with a pump. The environment within the chamber was monitored with an oxygen analyzer (model OA150; Servomex, Crowborough, England). Carbon dioxide was removed by self-indicating soda lime granules and excess humidity prevented by cooling of the recirculation circuit. Temperature within the chamber remained within $22-24^{\circ} \mathrm{C}$. The chamber was opened every other day for $\sim 2 \mathrm{~h}$ to clean the cages and replenish food and water. Rats were exposed to hypoxia for $7 \mathrm{~d}$ or $3 \mathrm{wk}$, and studied within $1 \mathrm{~h}$ of removal from the chamber. Another group was exposed to 3 wk of hypoxia but returned to normoxic conditions for $48 \mathrm{~h}$ before study.

\section{Isolated rat lungs}

Rats were anesthetized with sodium pentobarbital (40 mg i.p.). After tracheal cannulation, they were ventilated with warmed normoxic gas $\left(95 \%\right.$ air, $\left.5 \% \mathrm{CO}_{2}\right)$ at 60 breaths/min with an inspiratory pressure of 9 $\mathrm{cm} \mathrm{H}_{2} \mathrm{O}$ and an expiratory pressure of $2.5 \mathrm{~cm} \mathrm{H}_{2} \mathrm{O}$. A median sternotomy was performed and $100 \mathrm{IU}$ heparin administered through the right ventricle. After cannulae had been inserted into the pulmonary artery and the left ventricle, heart and lung were suspended in a humidified chamber at $37^{\circ} \mathrm{C}$ (Fig. 1). The lung was perfused through the pulmonary arterial cannula with a peristaltic pump at a constant flow of 0.05 $\mathrm{ml} / \mathrm{g}$ body weight/min. The recirculated perfusate was a physiological salt solution of the following composition (millimolar): $116 \mathrm{NaCl}, 4.7$ $\mathrm{KCl}, 19 \mathrm{NaHCO}_{3}, 0.83 \mathrm{MgSO}_{4}, 1.8 \mathrm{CaCl}_{2} 2 \mathrm{H}_{2} \mathrm{O}, 1.04 \mathrm{NaH}_{2} \mathrm{PO}_{4}, 5.5$ glucose, and phenol red $\mathrm{Na}(0.11 \mathrm{~g} /$ liter $)$, ficoll $(4 \mathrm{~g} / 100 \mathrm{ml}$, type 70 , Sigma Chemical Co., St. Louis, MO). Meclofenamate ( $3 \mu \mathrm{M})$ was included in the perfusate at the start of the experiment to inhibit prostaglandin synthesis. The lung was first flushed with $20 \mathrm{ml}$ of salt solution before recirculation with the perfusate (total volume, $30 \mathrm{ml}$ ) was initiated. Effluent perfusate was drained from the left ventricular cannula into a reservoir. Perfusate temperature was maintained at $38^{\circ} \mathrm{C}$. Mean

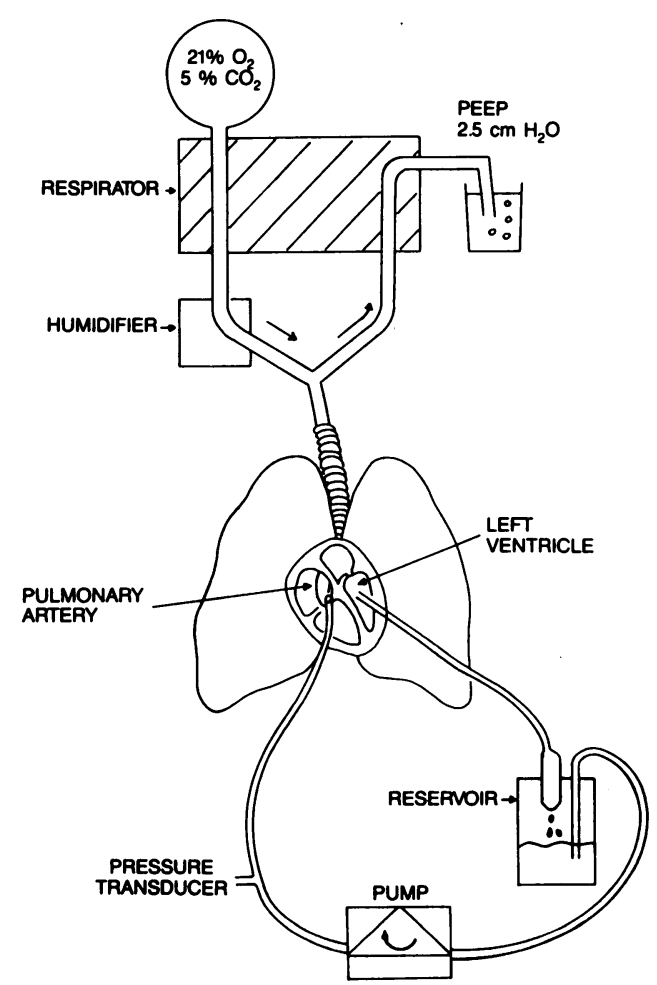

Figure 1. Experimental apparatus of the isolated rat lung. perfusion pressure was measured from a side port of the pulmonary arterial line (P23 XL transducer; Gould, Ballainvilliers, France), the pulmonary venous pressure was assumed to be zero. Each lung preparation was used to study only one of the following procedures.

Vasodilator response to acetylcholine. The endoperoxide analog U46619 was diluted in a 20 -ml volume of the physiological salt solution and infused into the pulmonary arterial line at a constant rate of 50 $\mathrm{pmol} / \mathrm{min}$ with an infusion pump (Vial-Medical, Grenoble, France). Infusion of U46619 was started after a 30-min equilibration period had elapsed. Pulmonary artery pressure increased gradually in response to U46619 and did not reach a plateau despite infusion was prolonged up to $20 \mathrm{~min}$. Acetylcholine chloride or its vehicle (saline) was injected into the pulmonary arterial line after $10 \mathrm{~min}$ of $\mathrm{U} 46619$ infusion as 50 $\mu \mathrm{l}$ bolus of increasing doses $\left(10^{-9}-10^{-6} \mathrm{M}\right)$ separated by 3-min intervals. To assess whether acetylcholine-induced vasodilation was blocked by EDRF inhibitors, separate experiments were performed after pretreatment with either methylene blue (final concentration, $10^{-4} \mathrm{M}$ ), pyrogallol $\left(3 \times 10^{-5} \mathrm{M}\right)$, hydroquinone $\left(10^{-4} \mathrm{M}\right)$ or their vehicles (ethanol or saline) added at the end of the equilibration period into the perfusate reservoir.

Vasodilator response to ionophore A23187. After $10 \mathrm{~min}$ of continuous infusion of $U 46619$ at $50 \mathrm{pmol} / \mathrm{min}$, ionophore $A 23187$ or its vehicle (diluted ethanol) was administered into the perfusate reservoir as $50 \mu$ bolus of increasing doses (final concentration, $10^{-9}-10^{-7} \mathrm{M}$ ) separated by 2 -min intervals.

Vasodilator response to sodium nitroprusside. After $10 \mathrm{~min}$ of continuous infusion of U46619 at $50 \mathrm{pmol} / \mathrm{min}$, sodium nitroprusside (AP $\mathrm{PCH}$, Paris) dissolved in isotonic glucose and protected from light was administered into the arterial line as $50 \mu \mathrm{l}$ bolus of increasing doses $\left(10^{-12}-10^{-7} \mathrm{M}\right)$, separated by $1-\mathrm{min}$ intervals.

Vasoconstrictor effect of endothelin. In another series of experiments, after 30 min equilibration, isolated lungs were challenged twice at 10-min intervals with a bolus of $0.25 \mu \mathrm{g}$ of angiotensin II injected into the arterial line. After return to baseline pressure, a $50 \mu \mathrm{l}$ bolus of $300 \mathrm{pM}$ endothelin was injected into the pulmonary arterial line. The responses to angiotensin II and endothelin were also studied in the presence of the antagonists of EDRF or their vehicles which were added in the perfusate reservoir as described above.

Histological studies. The lungs were fixed in the distended state by simultaneous infusion of $10 \%$ buffered formalin into the pulmonary artery and trachea at 30 and $20 \mathrm{~cm} \mathrm{H}_{2} \mathrm{O}$, respectively. The cannulae were clamped and the entire specimen was placed in a bath of $10 \%$ buffered formalin for $1 \mathrm{wk}$. Midsaggital slices ( $5 \mathrm{~mm}$ thick) were then processed. Sections $5-\mu \mathrm{m}$ thick were cut for light microscopy and stained with hematoxilin phloxin saffron. The endothelial coat was examined in proximal and distal arteries (range, 20-100 $\mu \mathrm{m}$ ) of lungs from normoxic and hypoxic rats.

\section{Drugs}

Meclofenamate purchased from Substantia (Orléans, France) and acetylcholine, methylene blue, pyrogallol, angiotensin II purchased from Sigma Chemical Co., were diluted in saline. Hydroquinone (Sigma Chemical Co.) was diluted in ethanol and prepared before each experiment. The endoperoxide analogue U46619 (Sigma Chemical Co.), the ionophore A23187 (Sigma Chemical Co.), both diluted in ethanol, and porcine endothelin (Novabiochem, Laüfelfingen, Switzerland), diluted in acetic acid $0.1 \mathrm{~N}$, were stored as stock solution at $-30^{\circ} \mathrm{C}$, and diluted with saline as required.

\section{Statistical analysis}

All results are expressed as mean \pm SEM. Two-way analysis of variance with repeated measurements were performed. To compare in the normoxic group the effects on pressure changes of acetylcholine or ionophore A23187 versus their vehicle, we tested drug effect, dose effect and interaction (23). Similarly, in the normoxic group, we also compared the effects of pretreatment with either methylene blue, hydroquinone, or pyrogallol on the response to acetylcholine. Because no significant difference between the three antagonists was found, results were pooled 
to compare in the normoxic group the effect of acetylcholine plús EDRF antagonists versus vehicle of acetylcholine. We also compared the effect of acetylcholine in the three different hypoxic groups and in the normoxic group, testing for group effect, dose effect, and interaction. Because interaction was significant, nonparametric Kruskals Wallis one-way analysis of variance and/or Mann-Whitney nonparametric test were used to compare groups at each dose of acetylcholine. A similar procedure was performed to compare the responses to ionophore A23187 in normoxic and hypoxic groups. One-way analysis of variance was also used to compare baseline perfusion pressure and the pressor response to endothelin, angiotensin II, and U46619 in the different groups. A $P$ value $<0.05$ was considered significant.

\section{Results}

Effects of acetylcholine and ionophore A23187 in lungs from normoxic rats. In lung preparations from normoxic rats, mean baseline pulmonary artery pressure was $7.4 \pm 0.2 \mathrm{mmHg}(n$ $=29)$ and increased by $6.2 \pm 0.1 \mathrm{mmHg}(n=24)$ within $10 \mathrm{~min}$ of $U 46619$ infusion $(50 \mathrm{pmol} / \mathrm{min})$. The pressor response to U46619 did not reach a plateau but continued to rise while repeated administrations of vehicle were performed to serve as control for acetylcholine or ionophore A23187 ( $n=5$ for each control curve, Figs. 2 and 3). When tested during baseline conditions, acetylcholine or ionophore A23187 had no effect on pulmonary arterial pressure. During conditions of increased pulmonary vascular tone by infusion of $U 46619$, acetylcholine or ionophore A23187 reduced the pulmonary artery pressure in a dose-dependent fashion ( $n=5$ for each dose response curve, Figs. 2 and 3 ). The vasodilator effects of acetylcholine and ionophore A23187 were only slightly affected by the degree of tone during this dose-response experimental period because maximal doses of these agents produced similar depressor effects when administered early during infusion of U46619. The addition of pyrogallol (Pyr), methylene blue (MB), or hydroquinone $(\mathrm{HQ})$ to the perfusate before starting the infusion of U46619 was without effect on baseline pulmonary artery pressure and did not significantly affect the pressor response to $\mathrm{U} 46619$ at $10 \mathrm{~min}(5.6 \pm 0.3 \mathrm{mmHg}, 5.3 \pm 0.2 \mathrm{mmHg}$, and $5.6 \pm 0.2 \mathrm{mmHg}$ with $\mathrm{Pyr}, \mathrm{MB}$, and $\mathrm{HQ}$, respectively). When examined in the presence of EDRF inhibitors, the vasodilatory response to acetylcholine was completely abolished and the

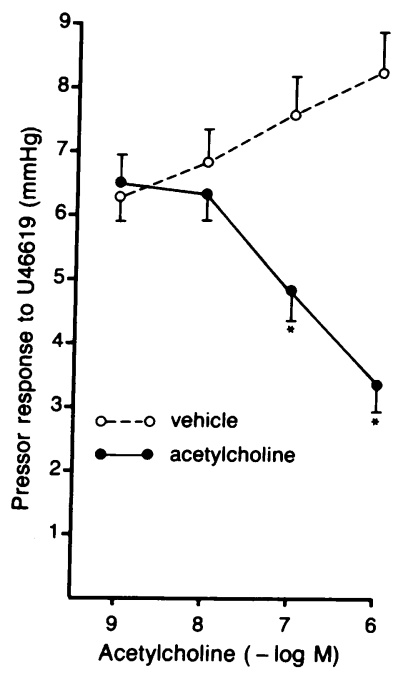

Figure 2. Vasodilatory response to acetylcholine in lungs from control normoxic rats during a continuous infusion of U46619 $(50 \mathrm{pmol} / \mathrm{min})$. Acetylcholine or vehicle (saline) was administered into the pulmonary arterial line as $50 \mu \mathrm{l}$ bolus of increasing doses $\left(10^{-9}-10^{-6} \mathrm{M}\right)$ separated by time intervals of $3 \mathrm{~min}$. (Open circles) Control curve obtained with repeated administration of saline; (closed circles) administration of acetylcholine. ${ }^{*} P<0.01$ for comparison with corresponding time control values measured with saline ( $n=5$ for each curve).

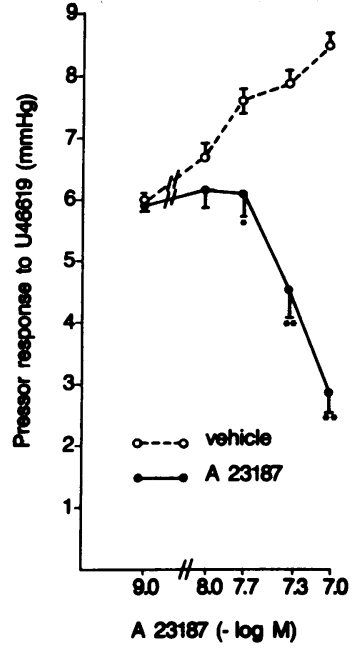

Figure 3. Vasodilatory response to ionophore A23187 in lungs from control normoxic rats during a continuous infusion of U46619 (50 $\mathrm{pmol} / \mathrm{min}$ ). Ionophore $\mathrm{A} 23187$ or vehicle (diluted ethanol) was administered into the perfusate reservoir as $50 \mu \mathrm{l}$ of increasing doses (final concentration, $10^{-9}-10^{-7} \mathrm{M}$ ) separated by time intervals of $2 \mathrm{~min}$. (Open circles) Administration of vehicle; (closed circles) administration of ionophore A23187. ${ }^{*} P<0.05 ;{ }^{* *} P$ $<0.01$ for comparison with corresponding time control values measured with vehicle $(n=5$ for each curve).

pressor response to $\mathrm{U} 46619$ was similar to that obtained with saline alone ( $n=5$ for each inhibitor, Fig. 4).

Effects of acetylcholine and ionophore A23187 in lungs from hypoxic rats. As compared to lungs from normoxic rats, mean baseline pulmonary artery pressure was increased in 1-wk-old hypoxic rats $(11.5 \pm 0.7 \mathrm{mmHg}, n=10, P<0.001)$ as well as in 3-wk-old hypoxic rats and in 3-wk-old hypoxic rats returned to room air (Table I). There was no significant difference of mean baseline pulmonary artery pressure between these groups of hypoxic rats. Similarly to lungs from normoxic rats, basal pulmonary artery pressure was not affected by administration of acetylcholine or ionophore A23187. The pressor responses to U46619 were similar in the three groups of hypoxic rats and were not significantly different from responses observed in control normoxic rats (Table I). The responses to acetylcholine $\left(10^{-6} \mathrm{M}\right)$ or ionophore A23187 $\left(10^{-7} \mathrm{M}\right)$, however, differed among groups of hypoxic rats (Figs. 5 and 6). The administration of acetylcholine $(n=5)$ or ionophore A23187 $(n=5)$ in lungs from rats exposed to 1 -wk-old hypoxia induced a decline of pulmonary artery pressure, but to a lesser extent than in control normoxic animals $(P<0.02)$. No vasodilatory effect of

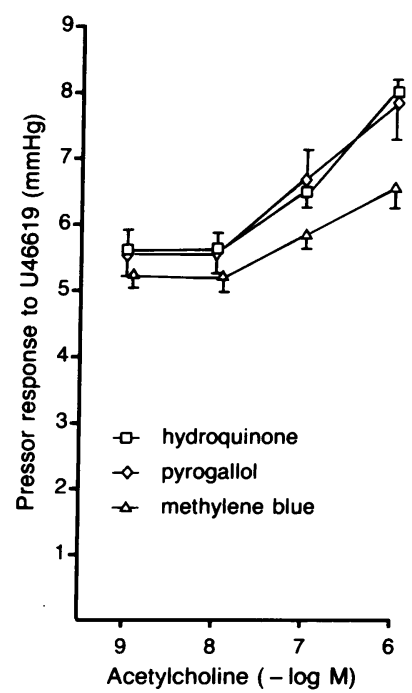

Figure 4. Effects of antagonists of endothelium-dependent relaxation on the vasodilator response to acetylcholine in lungs from normoxic rats. The antagonists hydroquinone $\left(10^{-4} \mathrm{M}\right)$, pyrogallol $\left(3 \times 10^{-5} \mathrm{M}\right)$ and methylene blue $\left(10^{-4} \mathrm{M}\right)$ were added to the perfusate reservoir $20 \mathrm{~min}$ before starting the infusion of U46619. The response to acetylcholine was examined after $10 \mathrm{~min}$ of $\mathrm{U} 46619$ infusion. There was no significant difference between responses to acetylcholine obtained in the presence of each of the antagonists. When pooled together, values obtained in the presence of the antagonists did not differ from control values obtained with repeated administration of saline alone $(n=5$ for each curve). 
Table I. Basal Pulmonary Perfusion Pressure and Pressure Changes Induced by Endothelin, Angiotensin II and U46619 in Lungs from Normoxic and Hypoxic Rats

\begin{tabular}{llcr}
\hline & Normoxia (control) & Hypoxia (3 wk) & Hypoxia (3 wk) + 48 h recovery \\
\hline $\begin{array}{l}\text { Basal pulmonary perfusion pressure }(\mathrm{mmHg}) \\
\text { Pressure changes }(\mathrm{mmHg})\end{array}$ & $7.4 \pm 0.2(n=29)$ & $13.3 \pm 0.6^{*}(n=19)$ & $13.0 \pm 0.6^{*}(n=15)$ \\
Endothelin $(300 \mathrm{pmol})$ & $1.6 \pm 0.2(n=5)$ & $6.8 \pm 0.5^{*}(n=6)$ & $1.8 \pm 0.3(n=5)$ \\
Angiotensin II $(0.25 \mu \mathrm{g})$ & $5.2 \pm 0.5(n=10)$ & $6.5 \pm 1.5(n=10)$ & $7.3 \pm 1.4(n=5)$ \\
U46619 $(50 \mathrm{pmol} / \mathrm{min})$ & $6.2 \pm 0.1(n=24)$ & $5.9 \pm 0.2(n=14)$ & $6.0 \pm 0.2(n=10)$ \\
\hline
\end{tabular}

Values are mean $\pm \mathrm{SE} .{ }^{*} P<0.001$ for comparison with corresponding values measured in lungs from normoxic control rats.

acetylcholine $(n=5)$ or ionophore $\mathrm{A} 23187(n=5)$ was noted in lungs from rats exposed to 3-wk-old hypoxia and instead a persistent rise of pulmonary artery pressure was observed (Figs. 5 and 6 ). This loss of receptor-mediated (acetylcholine) or nonreceptor-mediated (ionophore A23187) endothelium-dependent vasodilation, however, was no longer observed in rats exposed to a similar period of hypoxia but returned to room air for $48 \mathrm{~h}$ (Figs. 5 and 6). In this group, the pressor effect of U46619 was reduced to $3.4 \pm 0.4 \mathrm{mmHg}$ by $10^{-6} \mathrm{M}$ acetylcholine $(n=5),(3.3 \pm 0.3 \mathrm{mmHg}$ in the control normoxic group, NS) and to $2.6 \pm 0.3 \mathrm{mmHg}$ by $10^{-7} \mathrm{M}$ ionophore $\mathrm{A} 23187(n$ $=5),(2.7 \pm 0.4 \mathrm{mmHg}$ in the control normoxic group, NS). In lungs from rats returned to room air for a shorter period than $48 \mathrm{~h}$, only a partial recovery of the vasodilator response to acetylcholine or ionophore A23187 was observed. Thus, a period of $48 \mathrm{~h}$ recovery was chosen in these experiments.

To verify the viability of the endothelial cells in the lung preparations, histological studies were performed in isolated lungs challenged with U46619 and ionophore A23187. Light microscopic examination of 5- $\mu \mathrm{m}$ sections showed that pulmonary arteries in normoxic rats $(n=3), 3$-wk-old hypoxic rats $(n$ $=3$ ), and 3-wk-old hypoxic rats returned to room air $(n=3)$ exhibited in no instance areas of endothelial denudation. Thus, there was no evidence that endothelial damage caused by the experimental system could have predominated in lung preparations from chronically hypoxic rats.
Effect of sodium nitroprusside. There was no effect of sodium nitroprusside on baseline pulmonary arterial pressure in lungs from either control normoxic or 3-wk-old hypoxic animals. After the pulmonary vascular tone had been elevated by infusion of U46619, bolus administration of sodium nitroprusside caused a dose-dependent decrease of pulmonary arterial pressure (Fig. 7). In contrast to results obtained with acetylcholine, no significant differences were noted in the dose-dependent vasodilatory responses to sodium nitroprusside between 3 -wk-old hypoxic rats and control normoxic animals $(n=4$ for each dose-response curve, Fig. 7). Sodium nitroprusside similarly reduced the pressor response to U46619 in 1-wk-old hypoxic rats.

Effect of endothelin. As previously reported in lungs from normoxic rats (22), administration of $300 \mathrm{pM}$ endothelin induced a mild and prolonged increase of pulmonary artery pressure which was potentiated in the presence of EDRF antagonists. As shown in Fig. 8, addition of $\mathrm{MB}(n=5)$ or $\operatorname{Pyr}(n=5)$ to the perfusate significantly potentiated the pressor response to endothelin $(n=5)$. Experiments using HQ $(n=5)$ or its vehicle ethanol $(n=5)$ similarly demonstrated a potentiation of the response to endothelin in the presence of HQ (Fig. 9). In lungs from 3-wk-old hypoxic rats $(n=10)$, the pressor response to endothelin which was significantly higher than in lungs from control normoxic animals was no longer potentiated by $\mathrm{MB}$, Pyr or HQ (Figs. 8 and 9, $n=5$ with each antagonist). The
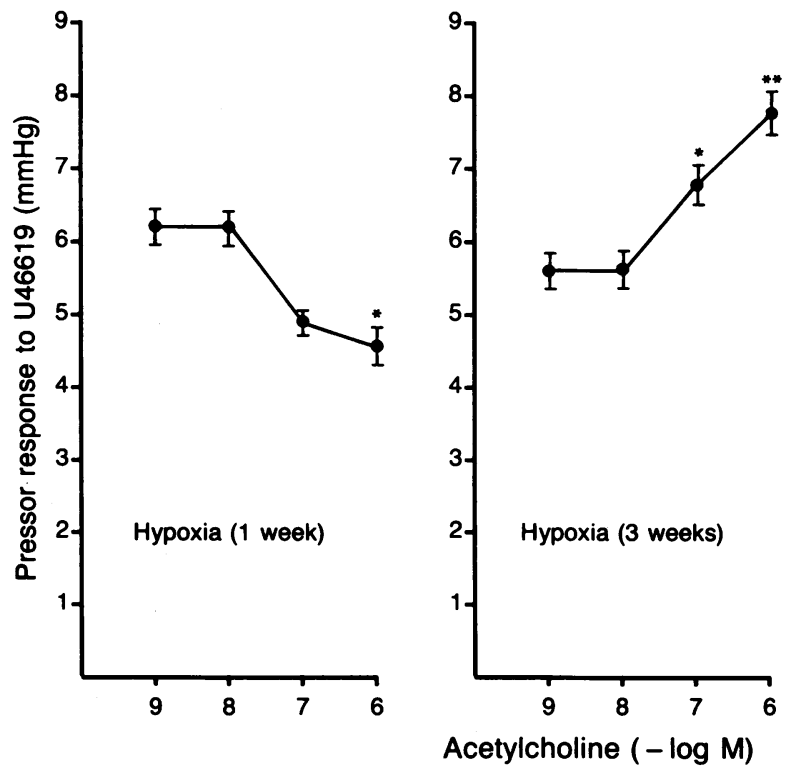

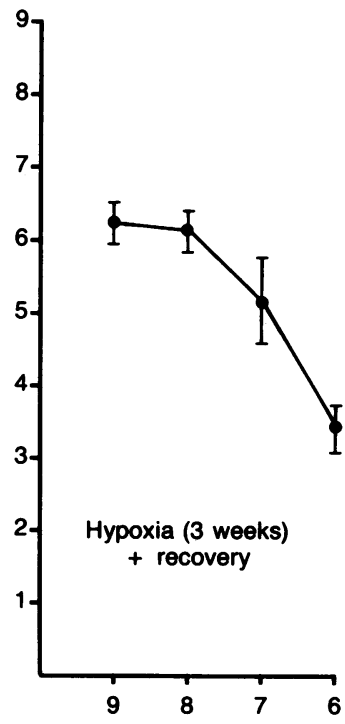

Figure 5. Response to acetylcholine in lungs from hypoxic rats during continuous infusion of U46619. The response to acetylcholine was examined in lungs from rats exposed to hypoxia during $1 \mathrm{wk}$ (left), $3 \mathrm{wk}$ (middle), or $3 \mathrm{wk}$ followed by a 48-h period of recovery to room air (right). ${ }^{*} P$ $<0.02 ;{ }^{* *} P<0.001$, for comparison with corresponding values measured in lungs from control normoxic animals $(n=5$ for each curve). 

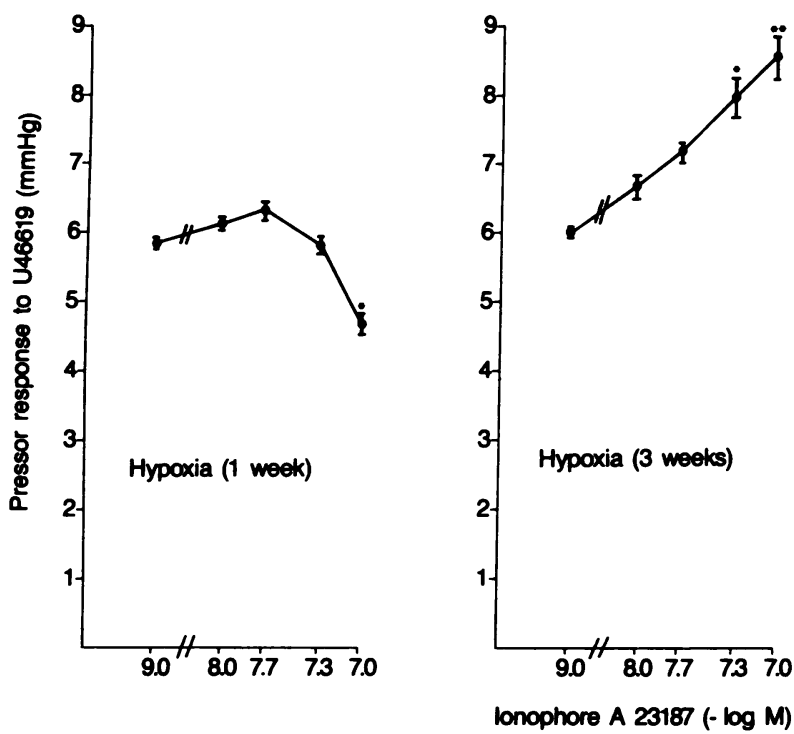

response to endothelin was also examined in lungs from rats exposed to 3-wk-old hypoxia and then returned to room air for $48 \mathrm{~h}(n=5)$. As shown on Table I, there was no difference between the response to endothelin in this group of rats and in the normoxic control group.

In contrast to the effects of endothelin which differed among groups, the response to $0.25 \mu \mathrm{g}$ angiotensin II which was constantly administered before endothelin in these experiments did not differ among hypoxic groups or between normoxic or hypoxic rats (Table I). Moreover, there was no potentiation of the effect of angiotensin II by EDRF antagonists. The pressor responses to angiotensin II were $4 \pm 0.3 \mathrm{mmHg}(n=5)$ and $4.1 \pm 0.2 \mathrm{mmHg}(n=5)$ in the presence of Pyr or MB, respectively, versus $5.1 \pm 0.4 \mathrm{mmHg}(n=5)$ after saline (NS), and was $5.3 \pm 0.4 \mathrm{mmHg}(n=5)$ in the presence of HQ versus $4.4 \pm 0.6 \mathrm{mmHg}(n=5)$ after ethanol (NS).

\section{Discussion}

This study demonstrates that endothelium-dependent dilation of the pulmonary vascular bed by acetylcholine or ionophore

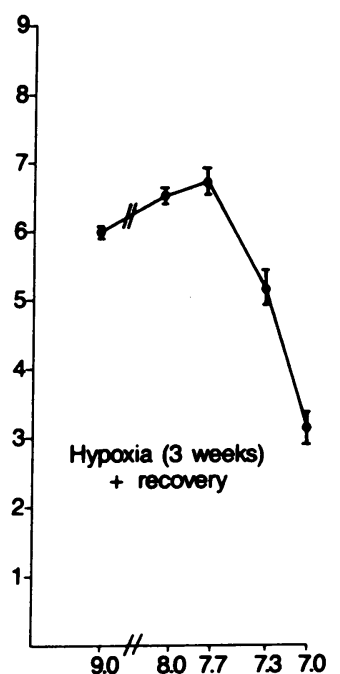

Figure 6. Response to ionophore A23187 in lungs from hypoxic rats during continuous infusion of U46619. The response to ionophore A23187 was examined in lungs from rats exposed to hypoxia during 1 wk (left), 3 wk (middle), or $3 \mathrm{wk}$ followed by a 48-h period of recovery to room-air (right). ${ }^{*} P<0.02 ;{ }^{* *} P<0.001$, for comparison with corresponding values measured in lungs from control normoxic animals ( $n=5$ for each curve).

A23187 is abolished in experimental hypoxic pulmonary hypertension. The dilator response to the endothelium-independent vasodilator sodium nitroprusside was not different from control suggesting that pulmonary hypertension does not result in a global defect of pulmonary smooth-muscle relaxation. The pulmonary vasoconstrictor response to endothelin was greater in chronically hypoxic rats compared to control normoxic animals and was not potentiated as in normoxic rats by EDRF inhibitors. These results suggest that one mechanism of altered vascular control in hypoxic pulmonary hypertension is impaired endothelium-dependent vasodilation.

Because Furchgott and Zawadski first reported that relaxation of rabbit aortic strips in response to acetylcholine required the presence of an intact endothelium (8), the existence of a substance passing from endothelial cells to vascular smooth muscle has been suggested by many studies (24). This factor has been termed EDRF, and shown to relax smooth muscle cells through activation of the soluble form of guanylate cyclase (25). The formation and release of EDRF has subsequently been demonstrated in response to a variety of pharma-

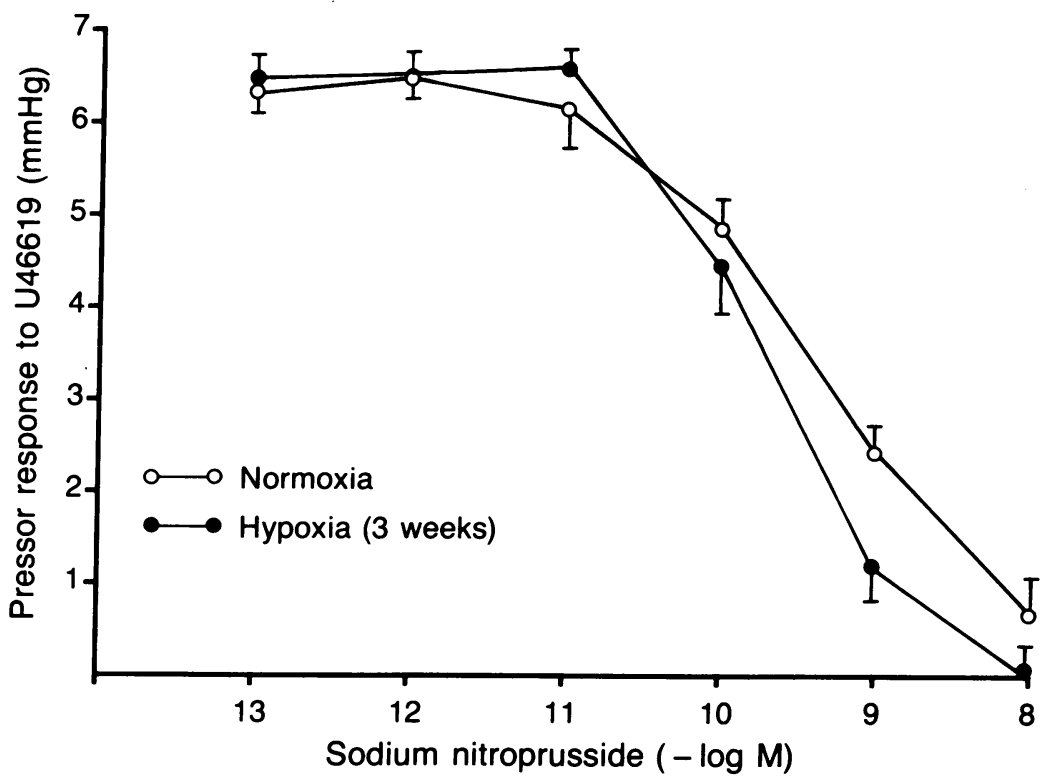

Figure 7. Vasodilatory response to sodium nitroprusside in lungs from rats exposed to room air (normoxia) or to hypoxia ( $3 \mathrm{wk}$ ) during continuous infusion of U46619. Sodium nitroprusside was administered into the pulmonary arterial line as $50 \mu \mathrm{l}$ bolus separated by time intervals of $1 \mathrm{~min}$. There was no significant difference between dose response curves obtained in lungs from normoxic or hypoxic rats ( $n$ $=4$ in each group). 

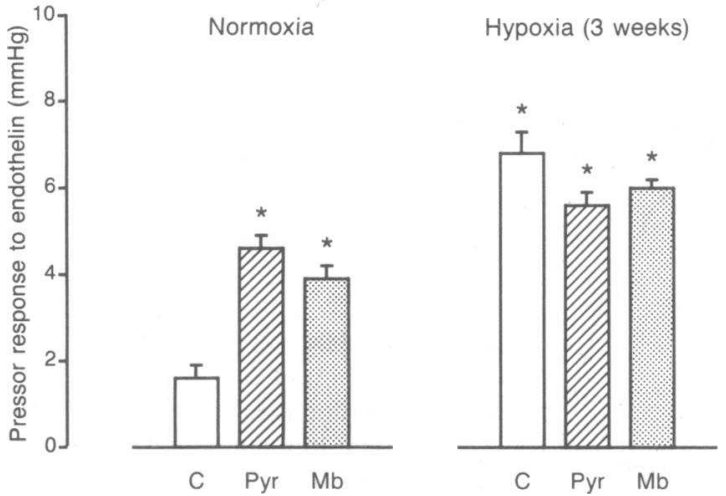

Figure 8. Pressure changes in lungs from rats exposed to room air (normoxia) or hypoxia ( $3 \mathrm{wk}$ ) induced by administration of $300 \mathrm{pM}$ endothelin in the absence $(C)$ or in the presence of the EDRF antagonists pyrogallol $\left(\mathrm{Pyr}, 3 \times 10^{-5} \mathrm{M}\right)$ or methylene blue $\left(\mathrm{Mb}, 10^{-4}\right.$ $\mathrm{M})$. Pyr and $\mathrm{Mb}$, or their vehicle (saline), were added to the perfusate reservoir $20 \mathrm{~min}$ before the injection of endothelin. The increase in perfusion pressure was measured 20 min after bolus administration of endothelin into the arterial line. ${ }^{*} P<0.001$ for comparison with normoxic controls ( $n=5$ in each group).

cological substances and physiologic stimuli, and shown to cause vasodilation in many vascular tissues and species (24). The pulmonary circulation may be highly sensitive to the effects of EDRF. Pulmonary artery strips from various species including humans relax in response to endothelium-dependent vasodilators $(14,24)$ and the intact pulmonary circulation from isolated lungs dilates in response to acetylcholine, bradykinin, and nitric oxide $(13,17,19)$. Moreover, in human studies, pulmonary vasodilation with acetylcholine has long been recognized and tentatively used in clinical practice (26).

In addition to promoting pulmonary vasodilation, EDRF can also attenuate vasoconstriction induced by pharmacological or physiological stimuli. In isolated perfused rat lungs, nonspecific inhibitors of EDRF (ecosatetrayenoïc acid, nordihydroguaiaretic acid, and hydroquinone) have all been reported to abolish acetylcholine-induced vasodilation and to enhance hypoxic pulmonary vasoconstriction (17). Methylene blue
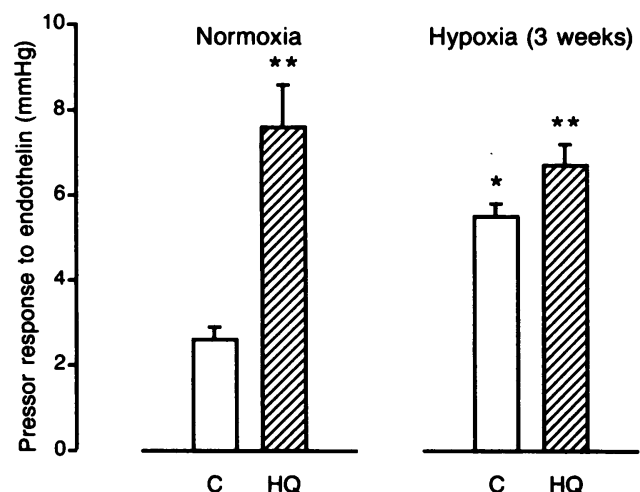

Figure 9. Pressure changes in lungs from rats exposed to room air (normoxia) or hypoxia ( $3 \mathrm{wk}$ ) induced by administration of $300 \mathrm{pM}$ endothelin in the absence $(C)$ or in the presence of hydroquinone $\left(\mathrm{HQ}, 10^{-4} \mathrm{M}\right)$. HQ or its vehicle (ethanol) were added to the perfusate reservoir $20 \mathrm{~min}$ before the injection of endothelin. ${ }^{*} P<0.01,{ }^{* *} P$ $<0.001$ for comparison with normoxic controls ( $n=5$ in each group). which can inhibit soluble guanylate-cyclase activity in smooth muscle cells and therefore the effect of EDRF, was also found to potentiate the pressor response to hypoxia in this model (18). More recently, $N$-monomethyl-L-arginine, a competitive inhibitor of the synthesis of nitric oxide from $\mathrm{L}$-arginine, was shown to enhance hypoxic vasoconstriction in pulmonary artery rings and isolated rat lungs (19). In a previous as well as in the present study, we found that the EDRF antagonists methylene blue, hydroquinone, and pyrogallol could potentiate the pulmonary pressor response to endothelin (22). Taken together, these observations suggest that endothelium plays a physiological role in modulating the pulmonary vascular tone through the release of EDRF.

The pulmonary circulation is a low-pressure, low-resistance system and it can be suggested that EDRF contributes to the low resting tone of the normal pulmonary vascular bed. Because EDRF inhibition in lungs from normoxic rats did not significantly affect baseline pulmonary artery pressure, it is unlikely that basal release of EDRF contributed to the low pulmonary vascular tone in our model of perfused rat lungs. In the present study, we investigated lungs of chronically hypoxic rats which had developed sustained pulmonary hypertension (27). Indeed, the basal perfusion pressure of lungs from rats exposed to 3 wk hypoxia was about twice that of control animals. Baseline pulmonary artery pressure, however, did not fall in response to sodium-nitroprusside, ionophore A23187 or acetylcholine in lungs from either normoxic or hypoxic rats. These observations are consistent with the absence of baseline tone in isolated lungs from either group while being ventilated with normoxic gas and suggest that high perfusion pressure in lungs from hypoxic rats mainly reflect pulmonary vascular remodeling. When the pulmonary vascular tone was increased by infusion of the endoperoxide analog U46619, a vasodilator response to the endothelium-dependent vasodilators acetylcholine and ionophore A23187 was observed in normoxic rats but not in chronically hypoxic rats. Because the response to the nonreceptor-mediated endothelium-dependent dilator ionophore A23187 was blocked to the same degree as that of the receptor-mediated endothelium-dependent vasodilator acetylcholine in chronically hypoxic rats, it is likely that a mechanism distal to receptor activation at endothelial cell level explained the inhibitory response to these agents. Sodium nitroprusside, in contrast, produced similar dose-related dilation in normoxic or chronically hypoxic rats. Sodium nitroprusside is known as a potent, nonendothelium-dependent, pulmonary vasodilator drug (28) which, similarly to acetylcholine or ionophore A23187, relaxes smooth muscle through activation of the soluble guanylate-cyclase (25). In contrast to acetylcholine or ionophore A23187, sodium-nitroprusside induces vasorelaxation by acting directly on vascular smooth muscle after conversion to nitric oxide and does not require the formation of EDRF (25). The dissimilar responses to acetylcholine and sodium nitroprusside in lungs from hypoxic rats would therefore suggest that there may be a dysfunction in the synthesis or release of EDRF by the endothelial cells of pulmonary arteries, rather than a defect in the response of vascular smooth muscle to EDRF. Interference of vasodilator prostaglandins with the effects described are unlikely because experiments were conducted in the presence of the cyclooxygenase inhibitor meclofenamate.

In agreement with these findings, we found that the pulmonary vasoconstrictor response to endothelin was greater in 
lungs from hypoxic rats than in those from normoxic controls. Moreover, pretreatment with EDRF antagonists, which greatly potentiated the vasoconstrictor response to endothelin in lungs from normoxic rats, had no effects in lungs from chronically hypoxic rats. The fact that similar concentration of methylene blue, hydroquinone, and pyrogallol can effectively block the vasodilator response to acetylcholine and enhance the pressor response to endothelin strongly suggests a common mechanism of action, i.e., inhibition of EDRF. This observation is consistent with the inability of pulmonary vessels from hypoxic rats to oppose endothelin-induced vasoconstriction by the release of EDRF and suggests that the defect of EDRF could explain the greater response to endothelin in lungs from hypoxic rats. An exaggerated response to vasoconstrictor stimuli in hypoxic rat lungs could also result from an increased wall-tolumen ratio of the hypertrophied pulmonary arteries. Such a possibility is unlikely because the pressor responses to the endoperoxide analog U46619 and to angiotensin II were similar in lungs from normoxic and hypoxic rats. Moreover, as also reported by others, the pulmonary pressor response to angiotensin II was not potentiated by EDRF antagonists (17).

The present results observed in lungs from chronically hypoxic rats are consistent with the loss of endothelium-dependent relaxation in pulmonary vessels. This observation conflicts with previous studies performed in isolated rat lungs showing that acute hypoxia stimulates EDRF production and release (17-19). Because exposures to hypoxia in these studies lasted only few minutes, it is possible that longer periods of moderate hypoxia are required to inhibit EDRF activity in pulmonary vessels. Indeed, anoxia has been shown to suppress rather than to stimulate EDRF activity in isolated pulmonary or systemic arteries $(24,29)$. More recently, endothelium-dependent relaxation and cyclic GMP accumulation have been shown to be selectively impaired by moderate hypoxia in isolated rabbit pulmonary arteries (30). Besides, the vasodilator activity of cultured bovine pulmonary endothelial cells stimulated by bradykinin has been reported to be abolished after a short exposure to severe hypoxia (31). Because severe hypoxia inhibits EDRF activity in vitro, it could be hypothetized that prolonged exposure to moderate hypoxia in vivo could affect endothelial function in the same way as the short-term exposure to severe hypoxia of vascular preparations.

It is, however, possible that the impairment of EDRF production could be secondary to the mechanical effects of chronic pulmonary hypertension rather than secondary to hypoxia per se. In rats exposed to only 1 wk hypoxia, we found that the vasodilation response to acetylcholine was reduced by only $26 \%$. These results are in agreement with the observation that precontracted pulmonary arterial segments from rats exposed to $10 \mathrm{~d}$ hypoxia develop only $68 \%$ of the response to acetylcholine compared with the relaxation in control rats (32) and suggest that the defect of endothelium-dependent relaxation develops gradually. Because longer exposure to hypoxia is also associated with pulmonary vascular remodeling and increased thickness of the vascular wall $(2,4)$, it could be suggested that mechanical factors could have interfered with the ability of EDRF to relax the hypertrophied smooth muscle. We therefore examined the responses to both endothelin and acetylcholine in lungs from chronically hypoxic rats after return to room air. We reasoned that a short recovery period would possibly reduce the increased tone associated to hypoxic pulmonary hypertension but would be insufficient to reverse the structural vascular remodeling of the pulmonary circulation (5). After a recovery period of $48 \mathrm{~h}$, the pulmonary vasodilator response to acetylcholine was fully recovered and the pulmonary vasoconstrictor response to endothelin was reduced to a similar magnitude than in control normoxic animals. Hence, the vasodilator defect cannot be explained solely on the basis of mechanical factors acting as a barrier to the diffusion of EDRF from endothelial cells to the smooth muscle.

A relationship between structural and functional changes of the pulmonary vascular wall is difficult to establish. Alterations of both structure and function of the endothelium occur during hypoxia and are reversed with room-air breathing $(2,4,5)$. Abnormal features in pulmonary arterial structure are known to develop progressively and pulmonary artery pressure to increase slowly during continuous exposure to hypoxia $(2,4)$. Yet some morphological changes appear as early as after $3 \mathrm{~d}$ of exposure to hypoxia and include intimal and subendothelial changes of pulmonary arteries $(5,6)$. Whether functional alterations of the pulmonary endothelium such as those described in this study represent a primary event or may be secondary to another disease process contributing to the development of pulmonary hypertension remains to be established. From our findings in lungs from 1-wk-old hypoxic rats, it could be suggested that impairment of endothelium-dependent relaxation may not represent an early defect during development of hypoxic pulmonary hypertension. Differences in the period of recovery are more striking. Most of the structural changes have been shown to reverse slowly on return to room air, and only a slight improvement is observed after a recovery period of $3 \mathrm{~d}(5)$. The functional recovery of pulmonary endothelium, measured after only $48 \mathrm{~h}$ of return to normoxia would therefore preceed the regression of structural changes induced by hypoxia.

The significance of these findings in relation to the increased tone and enhanced vasoreactivity of the pulmonary vascular bed previously described in hypoxic pulmonary hypertension is therefore of interest $(33,34)$. If endothelium-dependent relaxation is adversely affected by hypoxia in pulmonary vessels, then a potential vasodilatory resource may be lost in chronic hypoxic pulmonary hypertension that would theoretically lead to an increased tone and to an exaggerated or inappropriate vasoconstrictor response to various stimuli. Because EDRF is also a potent inhibitor of platelet adhesion and aggregation (35), such defect in EDRF production might also favor platelet agregation and, ultimately, thrombosis. The loss of pulmonary endothelium-dependent relaxation shown in the present study during experimental hypoxic pulmonary hypertension may prove important for the local regulation of pulmonary vascular tone and possibly for the prevention of thrombus formation. The significance of these findings with regard to patients with pulmonary hypertension in which pulmonary vascular tone is increased and intrapulmonary thrombus formation is frequent is therefore of interest and might be of clinical relevance.

\section{Acknowledgments}

The authors thank Dr. Christian Brun-Buisson for kindly reviewing the manuscript and are grateful to Mireille David and Sophie Rezali for expert assistance in preparing the manuscript.

\section{References}

1. Arias-Stella, J., and M. Saldana. 1963. The terminal portion of the pulmonary arterial tree in people native to high altitude. Circulation. 28:915-925. 
2. Meyrick, B., and L. Reid. 1983. Pulmonary hypertension: anatomic and physiologic correlates. In Clinics in Chest Medicine: Cardiovascular-Pulmonary Interactions in Normal and Diseased Lungs. Vol. 4. R. Matthay, M. Matthay, R Dantzker, editors. W. B. Saunders Co., Philadelphia. 199-217.

3. Harris, P., and D. Heath. 1986. Causes of pulmonary arterial hypertension In The Human Pulmonary Circulation. P. Harris and D. Heath, editors. Churchill Livingstone, Edinburgh. 226-238.

4. Rabinovitch, M., W. Gamble, A. S. Nadas, O. Miettinen, and L. Reid. 1979. Rat pulmonary circulation after chronic hypoxia: hemodynamic and structural features. Am. J. Physiol. 236:H817-H827.

5. Meyrick, B., and L. Reid. 1980. Endothelial and subintimal changes in rat hilar pulmonary artery during recovery from hypoxia. A quantitative ultrastructural study. Lab. Invest. 42:603-615.

6. Sjostrom, K., and J. D. Craps. 1983. Structural and biochemical adaptative changes in rat lungs after exposure to hypoxia. Lab. Invest. 48:68-79.

7. Brenner, B. M., J. L. Troy, and B. J. Ballermann. 1989. Endothelium-dependent vascular responses. J. Clin. Invest. 84:1373-1378.

8. Furchgott, R. F., and J. V. Zawadzki. 1980. The obligatory role of endothelial cells in the relaxation of arterial smooth muscle by acetylcholine. Nature (Lond.). 288:373-376

9. Palmer, R. M. J., A. G. Ferridge, and S. Moncada. 1987. Nitric oxide accounts for the biological activity of endothelium-derived relaxing factor. $\mathrm{Na}$ ture (Lond.). 327:524-526.

10. Yanagisawa, M., H. Kuhirara, S. Kimura, Y. Tomobe, M. Kobayashi, Y Mitsui, Y. Yasaki, K. Goto, and T. Masaki. 1988. A novel potent vasoconstricto peptide produced by vascular endothelial cells. Nature (Lond.). 332:411-415.

11. Hyman, A. L., E. W. Spannhake, and P. J. Kadowitz. 1978. Prostaglandins and the lung. Am. Rev. Respir. Dis. 117:111-136.

12. Voelkel, N. F., J. G. Gerber, I. F. McMurtry, A. S. Nies, and J. T. Reeves 1981. Release of vasodilator prostaglandin PGI2 from isolated rat lung during vascoconstriction. Circ. Res. 48:207-213.

13. Cherry, P. D., and C. N. Gillis. 1987. Evidence for the role of endothelium-derived relaxing factor in acetylcholine-induced vasodilation in the intact lung. J. Pharm. Exp. Ther. 241:516-520.

14. Greenberg, B., K. Rhoden, and P. J. Barnes. 1987. Endothelium-dependent relaxation of human pulmonary arteries. Am. J. Physiol. 252:H434-H438.

15. Hyman, A. L., P. J. Kadowitz, and H. L. Lippton. 1989. Methylene blue selectively inhibits pulmonary vasodilator responses in cats. J. Appl. Physiol. 66:1513-1517.

16. MacCumber, M. W., C. A. Ross, B. M. Glaser, and S. H. Snyder. 1989 Endothelin: visualization of mRNAs by in situ hibridization provides evidence for local action. Proc. Natl. Acad. Sci. USA. 86:7285-7289.

17. Brashers, V. L., M. J. Peach, and C. E. Rose. 1988. Augmentation of hypoxic pulmonary vasoconstriction in the isolated perfused rat lung by in vitro antagonists of endothelium-dependent relaxation. J. Clin. Invest. 82:1495-1502.

18. Mazmanian, G. M., B. Baudet, C. Brink, J. Cerrina, S. Kirkiacharian, and M. Weiss. 1989. Methylene blue potentiates vascular reactivity in isolated rat lungs. J. Appl. Physiol. 66:1040-1045.
19. Archer, S. L., J. P. Tolins, L. Raij, and E. K. Weir. 1989. Hypoxic pulmonary vasoconstriction is enhanced by inhibition of the synthesis of an endothelium-derived relaxing factor. Biochem. Biophys. Res. Commun. 164:1198-1205.

20. Lippton, H. L., T. A. Hauth, W. R. Summer, and A. L. Hyman. 1989. Endothelin produces pulmonary vasoconstriction and systemic vasodilation. $J$. Appl. Physiol. 66:1008-1012.

21. Rodman, D. M., I. F. McMurtry, J. L. Peach, R. F. O'Brien. 1989. Comparative pharmacology of rat and porcine endothelin in rat aorta and pulmonary artery. Eur. J. Pharmacol. 165:297-300.

22. Raffestin, B., S. Adnot, S. Eddahibi, I. Macquin-Mavier, P. Braquet, and P. E. Chabrier. 1990. Pulmonary vascular response to endothelin in rats. FASEB (Fed. Am. Soc. Exp. Biol.) J. 4:A275. (Abstr.)

23. Dixon, W. J., M. B. Brown, L. Angelman, J. W. Franc, M. A. Hill, R. S Sennrich, and J. D. Toporek. 1985. BMDP Statistical Software. University of California Press, Berkeley, CA.

24. Furchgott, R. F. 1984. The role of endothelium in the responses of vascular smooth muscle to drugs. Annu. Rev. Pharmacol. Toxicol. 24:175-197.

25. Murad, F. 1986. Cyclic guanosine monophosphate as a mediator of vasodilation. J. Clin. Invest. 78:1-5.

26. Harris, P., and D. Heath. 1986. Pharmacology of the pulmonary circulation. In The Human Pulmonary Circulation. P. Harris and D. Heath, editors Churchill Livingstone, Edinburgh. 183-209.

27. Raffestin, B., S. Adnot, J. J. Mercadier, M. Levame, P. Duc, P. Braquet, I. Viossat, and P. E. Chabrier. 1990. Synthesis and secretion of ANF during chronic hypoxia: a study in the conscious instrumented rat. Clin. Sci. 78:597-603.

28. Cigarini, I., S. Adnot, P. E. Chabrier, I. Viossat, P. Braquet, and B. Gaujour. 1989. Pulmonary vasodilator responses to atrial natriuretic factor and sodium nitroprusside. J. Appl. Physiol. 67:2269-2275.

29. De Mey, J. G., and P. M. Vanhoutte. 1981. Contribution of the endothelium to the response to anoxia in the canine femoral artery. Arch. Int. Pharmaco dyn. Ther. 253:325-326.

30. Johns, R. A., J. M. Linden, and M. J. Peach. 1989. Endothelium-dependent relaxation and cyclic GMP accumulation in rabbit pulmonary artery are selectively impaired by moderate hypoxia. Circ. Res. 65:1508-1515.

31. Warren, J. B., N. H. Maltby, D. MacCormack, and P. J. Barnes. 1989. Pulmonary endothelium-derived relaxing factor is impaired in hypoxia. Clin. Sci. 77:671-676.

32. Tozzi, C. A., and D. J. Riley. 1989. Endothelium-dependent relaxation of pulmonary artery rings from rats with hypoxic pulmonary hypertension. Am. Rev. Respir. Dis. 139:A175. (Abstr.)

33. McMurtry, I., M. D. Petrun, and J. T. Reeves. 1978. Lungs from chronically hypoxic rats have decreased pressor response to acute hypoxia. Am. J. Physiol. 235:H104-H109.

34. Emery, C. J., D. Bee, and G. Barer. 1981. Mechanical properties of reactivity of vessels in isolated perfused lungs of chronically hypoxic rats. Clin. Sci. 61:569-580.

35. Radomski, M. W., R. M. J. Palmer, and S. Moncada. 1987. The antiaggregating properties of vascular endothelium: interaction between prostacyclin and nitric oxide. Br. J. Pharmacol. 92:639-646. 